Brit. Heart f., 1969, 31, 63.

\title{
Haemodynamic Studies after Repair of Ventricular Septal Defect
}

\author{
M. S. GOTSMAN, W. BECK, C. N. BARNARD, AND V. SCHRIRE
}

From the Cardiac Clinic, Department of Medicine, Groote Schuur Hospital, the University of Cape Town; and the Council for Scientific and Industrial Research Cardiovascular-Pulmonary Research Group, Cape Town, South Africa

In patients with a ventricular septal defect, the size of the defect, reaction of the pulmonary vascular bed, and associated anatomical malformations determine the haemodynamic and clinical picture (Wood, Magidson, and Wilson, 1954; Schrire et al., 1965; Edwards, 1967). Thus, a small defect restricts transseptal flow, so that pulmonary flow and pressure increase only slightly. If the defect is larger, more flow is possible and the pressure rises. In patients with a non-restrictive defect, the pressures in the ventricles are similar, and severe pulmonary arterial hypertension occurs: the reaction of the pulmonary vascular bed and its resistance then governs the blood flow. Pulmonary arterial hypertension, therefore, may be a result of increased flow (hyperkinetic), vascular activity (vasoconstrictive), or organic vascular narrowing (obliterative), or a combination of these (Dammann and Ferencz, 1956; Vogel, Grover, and Blount, 1967a; Wood, 1958, 1959). These vascular changes may be a result of increased flow; transmitted pressure from the left ventricle (common ejectile force); pulmonary venous hypertension from a raised left atrial pressure (West and Dollery, 1960; Rudolph, Mesel, and Levy, 1963; West, Dollery, and Heard, 1964; Rudolph et al., 1964; Hoffman and Rudolph, 1965); reaction to local chemical factors-hypoxaemia, acidosis, and hypercarbia-from respiratory infections and lowered alveolar $\mathrm{Po}_{2}$ (Fishman, 1961; Bergofsky, Lehr, and Fishman, 1962; Vogel, McNamara, and Blount, 1967b), or even to individual reactivity to the same stimulus (Vogel, Pryor, and Blount, 1964; Naeye, 1965). Each kind of hypertension corresponds to histological changes in the elastic and muscular pulmonary arteries (Edwards, 1959; Heath and Edwards, 1958; Heath et al., 1958a, b; Wagenvoort et al., 1961; Harris and Heath, 1962).

Received May 28, 1968.
Patients with a ventricular septal defect can be classified according to their pulmonary arterial pressure and flow, as this determines the clinical picture and prognosis. Our simple classification, shown in the Table, subdivides patients who have a spectrum of the same disorder. Thus, they can be divided into three types according to the systolic pressure in the pulmonary artery expressed as a percentage of the systolic pressure in a systemic artery (PSP/SSP). The ranges 0-40, 40-80, and more than 80 , are arbitrary figures to subdivide patients with mild, moderate, or severe pulmonary arterial hypertension. Similarly, the left-to-right shunt, expressed as a percentage of pulmonary blood flow, indicates a minimal, moderate, or gross increase in pulmonary blood flow. Thus patients with a Type 1 ventricular septal defect have a PSP/SSP of less than 40 per cent: those in Type 1A have a minute defect with a left-to-right shunt of less than 10 per cent; in Type 1B, a slightly larger defect with a left-to-right shunt of 10-40 per cent and a still larger defect in Type 1C where the left-to-right shunt is greater than 40 per cent. A special subgroup of patients have outflow tract obstruction to the outflow tract of the right ventricle but have the haemodynamics of Type 1C: they have been called Type 1C with gradient. Patients in Type 2 have defect of moderate size with a PSP/SSP of 40 to 80 per cent; they all had large left-to-right shunts. Patients in Type 3 have large ventricular septal defects and the systolic pressures in the two great vessels are equal or nearly equal: those with a large left-to-right shunt of more than 40 per cent and in whom pulmonary arterial hypertension is due to a high pulmonary blood flow are classified as Type $3 \mathrm{~A}$, but those with a very high pulmonary vascular resistance and a left-to-right shunt of less than 40 per cent are placed in Type 3B. We have postulated that patients with Type 1 have normal mus- 
TABLE

CLASSIFICATION OF PATIENTS WITH A VENTRICULAR SEPTAL DEFECT (Figures in parentheses indicate the number of patients in each group)

\begin{tabular}{|c|c|c|c|c|}
\hline & & \multicolumn{3}{|c|}{$\begin{array}{l}\text { Left-to-right shunt expressed as percentage of } \\
\text { pulmonary blood flow }\end{array}$} \\
\hline & & $0-10$ & $10-40$ & $>40$ \\
\hline $\begin{array}{l}\text { Systolic pressure in pulmonary } \\
\text { artery expressed as percentage } \\
\text { of systolic pressure in systemic } \\
\text { artery }\end{array}$ & $\begin{array}{r}0-40 \\
40-80 \\
>80\end{array}$ & $\begin{array}{c}\text { Type 1A } \\
(0) \\
\text { Type } 3 B \\
(0)\end{array}$ & $\begin{array}{l}\text { Type 1B } \\
\text { (2) } \\
\text { Type } 3 B \\
(0)\end{array}$ & $\begin{array}{c}\text { Type 1C } \\
\text { (5) } \\
\text { Type 2 } \\
\text { (9) } \\
\text { Type 3A } \\
\text { (11) }\end{array}$ \\
\hline
\end{tabular}

Note: Type 1B or 1C may also be associated with organic obstruction to the outflow tract of the right ventricle ( 7 patients).

cular pulmonary arteries, those with Type 2 have vasoconstrictive changes, and those with Type $3 \mathrm{~A}$ and Type 3B have vasoconstrictive and increasing degrees of obliterative changes (Wagenvoort, 1960; Wagenvoort et al., 1967).

Our surgical policy was to close the ventricular septal defect in patients over the age of 5 years if they had a left-to-right shunt of more than 40 per cent of pulmonary blood flow; if they had a low pressure and a shunt of less than 40 per cent (Types 1A and 1B), they were considered to have a small defect and a good prognosis without operation; if they had a high pressure and a small shunt (Type 3B), then they were considered to have severe pulmonary vascular disease, surgery was associated with an appreciable mortality, and limited clinical benefit was produced. The defect was closed in younger children if they had severe symptoms, but we preferred not to undertake corrective surgery if they weighed less than $10 \mathrm{~kg}$.

This paper will describe the haemodynamic findings measured one year after corrective surgery in an unselected group of patients with an isolated ventricular septal defect, to assess the ability of the pulmonary vascular abnormalities to return to normal.

\section{Patients and Methods}

We studied a consecutive group of patients who had a ventricular septal defect closed between 1958 and 1965. Patients with other significant defects (patent ductus arteriosus, aortic incompetence, or mitral valve disease) or a residual defect after operation, were excluded. A limited post-operative investigation was undertaken in 5 patients with a low pulmonary arterial pressure: an indicator dilution curve was examined to prove that the defect had been closed; intravascular pressures were not measured as they were probably normal; these patients have also been excluded from this study.

We saw all patients several times before operation and at regular intervals thereafter. All our patients are well after operation, they have no symptoms, and have had a spurt in growth. The chest deformity has im- proved and the heart size has decreased. Their only residual abnormalities are a soft outflow tract murmur in a few patients and varying degrees of right bundlebranch block (Beck, Schrire, and Vogelpoel, 1964).

Routine right heart catheterization was undertaken before and one year after corrective operation. Pulmonary capillary wedge pressures were recorded in all the patients and pulmonary vascular resistance was calculated. Most of the patients were young children, and we used indices (per square metre of body surface area) to compensate for differences in body size or changes due to growth. The peak systolic pressure in the pulmonary artery was expressed as a percentage of systemic arterial pressure (PSP/SSP). Ascending aortic or left ventricular pressures were not measured in the postoperative studies, so that similar measurements were compared to allow for peripheral amplification observed in systemic pressures. Similarly, the pulmonary vascular resistance index was expressed as a percentage of systemic vascular resistance index (PVRI/SVRI). Cardiac output was measured by the direct Fick principle or from indicator dilution curves using a constant flow arterial sampling system.

Right ventricular and systemic arterial pressures were measured and compared at the end of operation in 8 patients with a Type $3 \mathrm{~A}$ ventricular septal defect.

The size of the defect was estimated at the time of operation; its area was calculated and then expressed as square $\mathrm{cm}$. per square metre of body surface area. This was only a rough approximation, since the size was estimated by the surgeon, the defect was often oval, rarely round, and the size was occasionally distorted by retraction.

Selective pulmonary angiography was performed in 5 patients at the time of post-operative study.

\section{Results}

These differed in the various subgroups.

Type 1B. Two patients with a left-to-right shunt of less than 40 per cent were studied. After operation, pulmonary blood flow returned to normal, arterial pressure fell slightly, and there was no change in vascular resistance (Fig. 1a and 2a). 

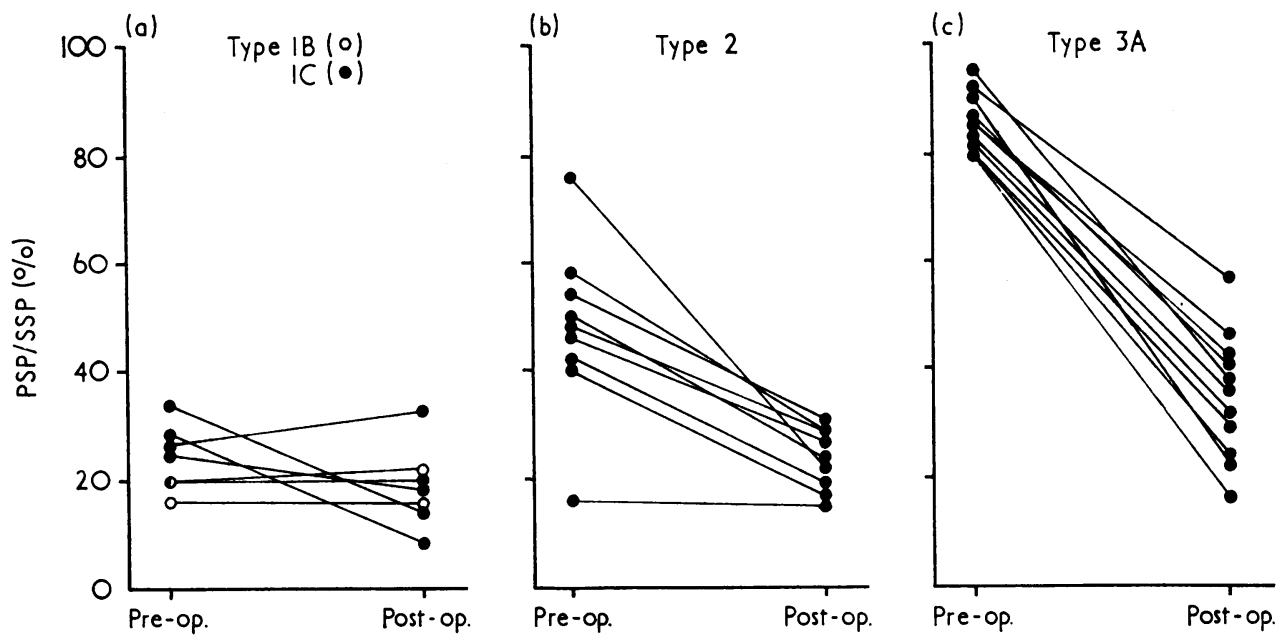

FIG. 1.-Changes in pulmonary artery pressure after closure of a ventricular septal defect. The peak systolic pressure in the pulmonary artery (PSP) was expressed as a percentage of the peak systolic pressure (SSP) in a systemic artery (PSP/SSP\%). Measurements were made before, and one year after operation. (a) Types 1B and 1C. Pulmonary arterial pressure was normal or slightly raised before operation and either fell to normal or did not change afterwards. (b) Type 2. Pre-operative PSP/SSP ranged between 40 and 80 per cent except in one patient with functional infundibular stenosis. Pulmonary arterial pressure fell significantly after operation. (c) Type $3 A$. PSP/SSP was greater than 80 per cent before operation. It decreased significantly when the defect was closed, but remained abnormal in some patients.

.his passive result was secondary to a decrease in ulmonary blood flow. The ventricular septal deects ranged in size from 0.5 to $1.4 \mathrm{~cm} .^{2} / \mathrm{m}^{2}$, with mean of $0.9 \mathrm{~cm} .^{2} / \mathrm{m}^{2}$.

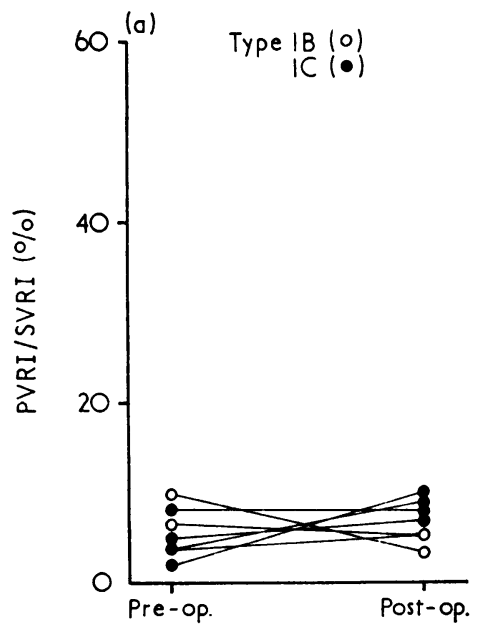

These operations were undertaken early in our surgical experience and we would not surgically close or operate on such small defects at the present time.

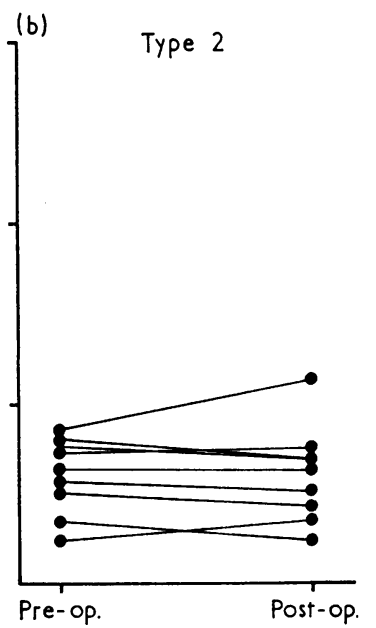

FIG. 2.-Changes in pulmonary vascular resistance after closure of a ventricular septal defect. Pulmonary vascular resistance index was expressed as a percentage of systemic vascular resistance (PVRI/SVRI\%). Calculations were based on measurements made before and one year after operation. (a) Type $1 B$ and $1 C$. The ratio was normal before operation and did not change after the defect was closed. (b) Type 2 . The ratio was normal or slightly raised, and it did not change when the defect was closed. (c) Type $3 A$. The ratio was moderately or greatly raised in all the patients. After operation it decreased in 4, remained constant in 4, increased slightly in 2 , and much in 1 . 
Type 1C. Complete studies were undertaken in 5 patients. The defects ranged in size from 0.5 to $1.2 \mathrm{~cm} .{ }^{2} / \mathrm{m}^{2}$, with a mean of $0.8 \mathrm{~cm} .{ }^{2} / \mathrm{m}^{2}$ Before operation they had a slightly raised pulmonary arterial pressure (mean PSP $/ \mathrm{SSP}=26 \%$ ), large leftto-right shunt (mean $=57 \%$ ), and a normal pulmonary vascular resistance (mean PVRI/SVRI $=4 \%$ ). After the defect was closed, the pulmonary flow returned to normal, pressure changed little (mean PSP $/$ SSP $=19 \%$ ), and there was little significant change in vascular resistance (mean PVRI/SVRI = $8 \%$ ), the change being a passive response to a reduction in pulmonary blood flow (Fig. 1a and 2a).

Type 2. Nine patients were studied. The defect was larger, ranging from 1.2 to $4.0 \mathrm{~cm} .{ }^{2} / \mathrm{m}^{2}$, with a mean of $2.4 \mathrm{~cm} .{ }^{2} / \mathrm{m}^{2}$ Before operation, they had a higher pulmonary arterial pressure than

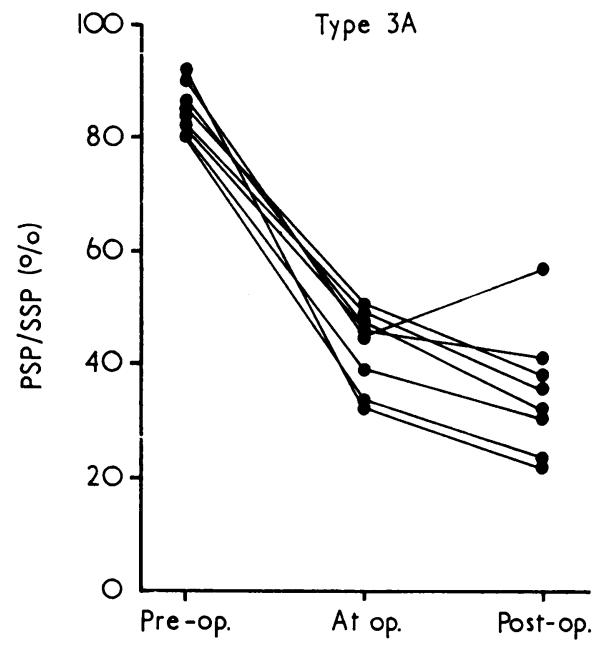

FIG. 3.-Serial changes in pulmonary artery pressure. PSP/SSP was measured before operation, at the end of operation, and then one year later at post-operative catheterization in patients with Type 3A defects (compare with Fig. 1C). Pulmonary arterial pressure decreased immediately when the defect was closed and there was slight subsequent improvement.

the Type $1 \mathrm{C}$ (mean PSP $/ \mathrm{SSP}=51 \%$ ), with a similar flow (mean left-to-right shunt $=61 \%$ ) and thus a higher vascular resistance (PVRI/SVRI $=12 \%$ ). Again, after operation, the fall in pulmonary arterial pressure $(\mathrm{PSP} / \mathrm{SSP}=23 \%$ ) was a passive response to a fall in blood flow, and there was little change in vascular resistance (PVRI/SVRI $=11 \%$ ) (Fig. 1b and $2 b$ ). These patients were left with a higher pulmonary arterial pressure and resistance than Type $1 \mathrm{C}$.
Three patients had a significant pressure gradient across the outflow tract of the right ventricle: infundibular resection was not performed, and the gradient has since disappeared $(65 \mathrm{~mm}$. $\mathrm{Hg}$ in one patient). This was probably due to an abnormal crista supraventricularis producing mild functional stenosis in the presence of a large pulmonary blood flow.

Post-operative pulmonary angiograms in 2 patients were normal: the radiologically visible smaller pulmonary arteries appeared to be normal.

Type 3A. Eleven patients were studied. They had even larger septal defects, ranging in size from 1.0 to $4.5 \mathrm{~cm} .{ }^{2} / \mathrm{m}^{2}$, with a mean of $2.6 \mathrm{~cm} .{ }^{2} / \mathrm{m}^{2}$. They had more severe pulmonary hypertension (PSP $/ \mathrm{SSP}=85 \%$ ) due to a higher vascular resistance (PVRI/SVRI $=27 \%$ ), though the blood flow was similar to Type 2 (mean left-to-right shunt = $61 \%$ ). Pulmonary arterial pressure fell significantly after operation (PSP $/ \mathrm{SSP}=28 \%$ ), with only a slight fall in vascular resistance (PVRI/SVRI $=24 \%$ ) (Fig. 1c and 2c). The change in vascular resistance was variable: it fell in 4 , was unchanged in 4 , and increased in 3, but a conspicuous increase was observed in only one. This response was not related to the age of the patient, magnitude of the shunt, pulmonary vascular resistance, or pulmonary capillary wedge pressure. Serial changes in PSP/SSP are shown in Fig. 3.

The patients were left with a much larger pulmonary artery pulse pressure (mean $=26 \mathrm{~mm}$. $\mathrm{Hg}$ ) than patients with a Type 2 septal defect (mean = $18 \mathrm{~mm} . \mathrm{Hg}$ ) which in turn was larger than in patients with a defect of Type $1 \mathrm{C}$ (mean $=13 \mathrm{~mm}$. $\mathrm{Hg}$ ) or Type $1 \mathrm{~B}$ (mean $=12 \mathrm{~mm}$. Hg) (Fig. 4).

Post-operative pulmonary arteriograms were performed in 3 patients. Peripheral attenuation of the smaller pulmonary arteries was seen in 2 (Fig. 5); one showed a rise in PVRI/SVRI while the other did not change: the vessels were normal in another who also had no change in pulmonary vascular resistance.

Patients with Significant Outflow Tract Obstruction that Needed Correction at Time of Operation (Type 1C with gradient). Seven patients had significant obstruction to the outflow tract of the right ventricle: in consequence they had similar systolic pressures in the right and left ventricles but a nearnormal pressure in the pulmonary artery. Thus they form a specific subgroup of Type 1C. They had significant left-to-right shunts and PSP/SSP was less than 40 per cent. Four had an abnormal crista supraventricularis and only needed an infundibular resection, one had pulmonary valve 
stenosis and had a pulmonary valvotomy, while the other 2 had both. The pulmonary vascular resistance increased slightly in 3 patients, fell in 1 , and was unchanged in 3 . The over-all changes were not really significant.

Pulmonary Arterial Wedge Pressure and Response to Operation. Fig. 6a shows the pulmonary capillary wedge pressures measured before operation. Patients with increasing pulmonary flow and pressure had raised wedge pressures. After operation the pressures returned to normal in all the patients (Fig. 6b).

Individual changes in the Type 3a patients are shown in Fig. 7. The patients were subdivided according to the change in PVRI/SVRI after operation. There was little difference between the three groups.

\section{Discussion}

Two changes persist after closure of a ventricular septal defect: (1) Varying degrees of right bundlebranch block and (2) residual changes in the pulmonary vascular tree.

Type 1B and 1C patients had a normal resistance before operation and this did not change after operation. Type 2 patients also showed little change in PVRI/SVRI. This confirms the findings of Adams et al. (1961) and Braunwald, Braunwald, and Morrow (1962), who found little change in pulmonary vascular resistance after closure of the defect in patients with a Type $1 \mathrm{C}$ and 2 ventricular septal defect. A variable change in resistance occurred in patients in Type 3A. Presumably these patients had different degrees of vascular disease before operation, but the lack of change in many of the Type 2 and 3A patients suggests that significant intimal fibrosis was present. Quantitative studies by Wagenvoort et al. (1961) have shown that in children with a large ventricular septal defect, intimal proliferation is invariably present after the first year and is obvious by the age of 3 years. In all our patients the pulmonary artery pressures fell at the end of operation to close the defect, and only slight further improvement was noted in the subsequent year. Once the defect is closed the ratio PSP/SSP is similar to PVRI/SVRI because pulmonary and systemic flows are equal; but the relation is not valid if an unsteady state exists when the pressures are measured at operation or if the left atrial pressure is abnormal. This relatively constant relation of PSP/SSP in the year after operation indicates that much of the improvement occurs immediately, when the offending pressure and flow stimuli are removed, that in a few patients medial hypertrophy regresses, but that the

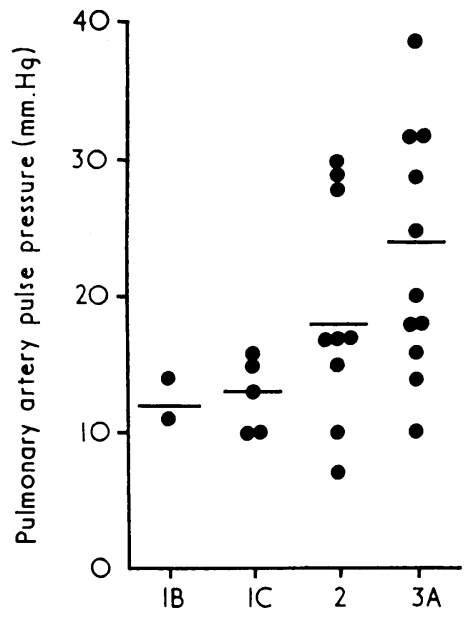

Fig. 4.-Pulse-pressure in the pulmonary artery. Measurement made one year after closure of the defect. Patients with Type 2 and 3A ventricular septal defects had a large pulse pressure indicating abnormal distensibility of the elastic pulmonary arteries. Horizontal bars indicate mean values.

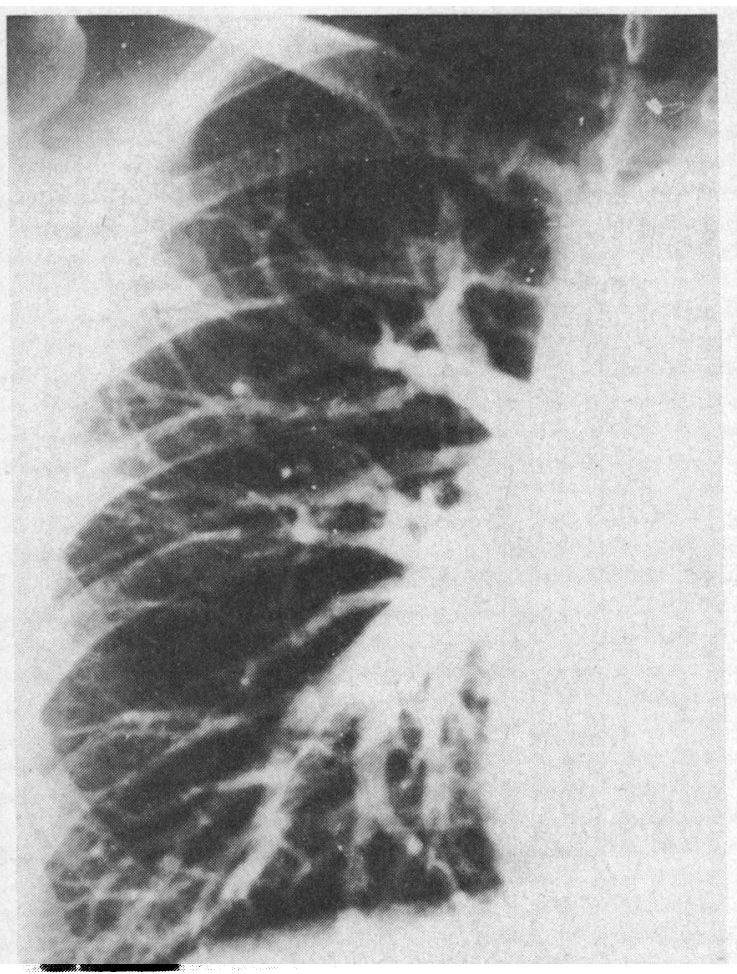

Fig. 5.-Abnormal pulmonary arteriogram one year after operation. Right pulmonary arteriogram (artero-posterior position) in an 8-year-old boy with a Type $3 \mathrm{~A}$ ventricular septal defect in whom the PVRI/SVRI increased from 15-28 per cent. The major pulmonary arteries and their branches are normal, but fine arborization of the peripheral radicles cannot be seen. 

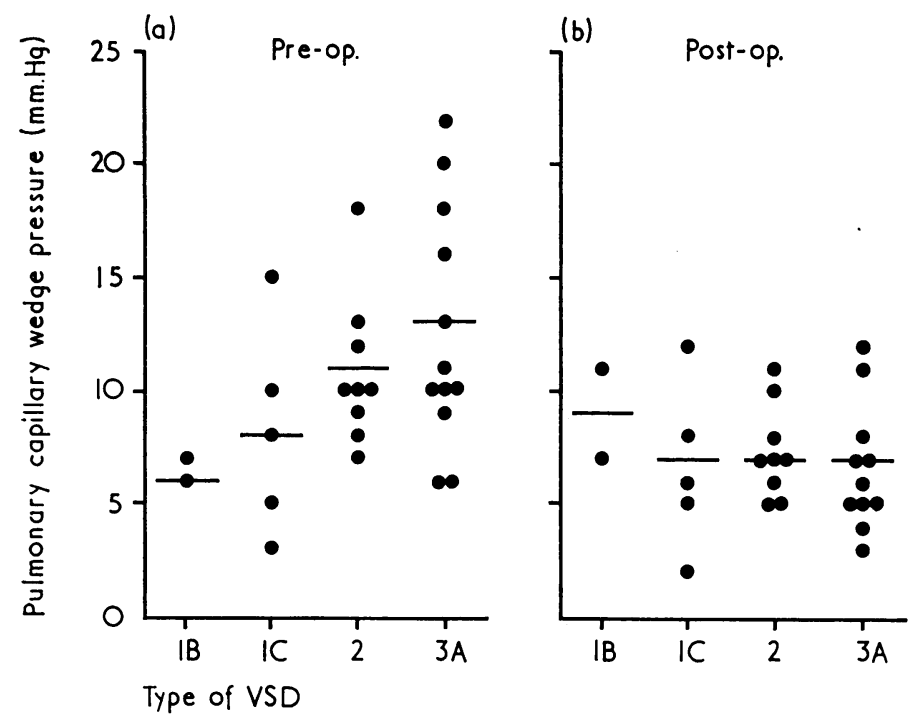

Fig. 6.-Pulmonary capillary wedge pressure. Pressures were measured (a) before, and (b) one year after closure of the defect. Patients classified according to the text. Horizontal lines indicate mean values. The pulmonary capillary wedge pressure was raised in patients with increased pulmonary arterial flow and pressure, but returned to normal when the defect was closed.

majority have significant intimal fibrosis and no change occurs. These findings correspond to the observations of Cartmill et al. (1966) who also found a variable response in Type $3 \mathrm{~A}$ patients.

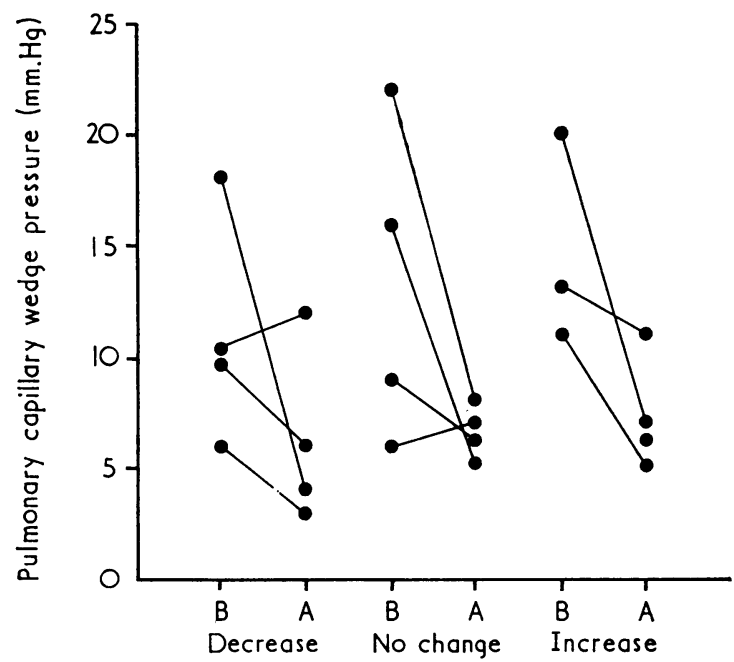

Change in PVRI/SVRI

Fig. 7.-Pulmonary capillary wedge pressures in Type 3A patients. The patients were divided into 3 groups according to the change in PVRI/SVRI measured before (B) and one year after (A) operation. Pulmonary capillary wedge pressures tended to fall, but the change was not related to the alteration in pulmonary vascular resistance.
They found that the PVRI/SVRI increased in 7 patients, remained constant in 14, and decreased in the remainder of the series of 42 patients. Lillehei et al. (1964) showed progressive improvement in PVRI in 5 of 6 patients undergoing serial postoperative catheterization over an 8-year period, thus demonstrating further long-term reversibility of the structural changes. However, there were notable exceptions and there were patients in whom the PVRI increased. The ultimate outcome in this group of patients is unpredictable. In our patients the increase in pulmonary arterial flow and pressure was associated with a raised left atrial pressure, and these levels could not be related to the result after operation.

Apart from residual structural changes in the muscular pulmonary arteries, alternative hypotheses to explain the persistent abnormality and constant pulmonary vascular resistance included redistribution of pulmonary blood flow when the pulmonary arterial pressure is reduced, critical closure of the thickened, more reactive vessels when the distending pressure is removed (Burton, 1951), or possibly a homeostatic baroceptor mechanism in the pulmonary artery sensitive to the pulmonary vascular resistance.

The unusual post-operative pulmonary artery pulse pressure is an indication of an abnormal pulmonary vascular bed. The diastolic pressures were similar in all the patients except Type 3A. These changes indicate a persistently low compliance and 
inextensibility of abnormal major pulmonary arteries (Harris, Heath, and Apostolopoulos, 1965).

Of the 5 post-operative pulmonary arteriograms, 2 were abnormal: the vascular resistance was unchanged in one Type 3A patient and had increased in another. This demonstrated macroradiological structural changes which were still present one year after operation.

Our results are limited. We did not study the pulmonary vascular bed under different conditions: flow can be increased by muscular exercise or by occluding a major pulmonary artery with a balloon catheter; in this way a pressure-flow relation can be established for each patient, and this provides information about the distensibility characteristics of the pulmonary vascular bed (Kimball and McIlroy, 1966). Vasodilator drugs were not administered. Phenylephrine, a potent pulmonary vasoconstrictor, was given to 17 subjects before operation and the results have been reported (Vogelpoel et al., 1962). We studied only 4 patients after operation. Too few comparable studies were undertaken and we have, therefore, not included these results.

Natural History of Patients with Ventricular Septal Defect: Correct Time for Surgical Intervention. Patients with a ventricular septal defect may follow one of three courses: often the defect may close, usually the haemodynamic status remains constant, or rarely the pulmonary vascular changes increase in severity (Bloomfield, 1964).

Hoffman and Rudolph (1965) showed, in an unselected group of infants with a ventricular septal defect, that the defect closed spontaneously in 36 per cent and decreased in size in 28 per cent. It was common between 7 and 12 months of age, and with small or large defects, and often in children with congestive heart failure and pulmonary arterial hypertension (Kidd et al., 1965a, b). Infundibular obstruction may also develop: a form of spontaneous banding of the outflow tract of the right ventricle (Arcilla et al., 1963; Gotsman, 1966). These factors ameliorate the natural history of the condition, but there are still patients who show a progressive rise in pulmonary arterial pressure, a fall in flow, and an increase in resistance. This starts in the first year of life, but becomes more severe in older children (4-10 years), until the mounting resistance diminishes and reverses the left-to-right shunt (Lucas et al., 1961; Stanton and Fyler, 1961; Arcilla et al., 1963; Auld, Gibbons, and McGregor, 1963; Weidman, DuShane, and Kincaid, 1963; Farrar and Dunlop, 1965; Kidd et al., 1965a, b; Anderson et al., 1967). Thus, it has been suggested that all infants with a suspected ventricular septal defect should be catheterized in infancy if the clinical and other criteria suggest a large pulmonary flow or high pressure, and that infants with a Type $1 \mathrm{C}$, 2 , or $3 \mathrm{~A}$ defect should be recatheterized 6 months to 2 years later, to anticipate an increase in pulmonary vascular resistance (Hoffman and Rudolph, 1965; Kidd et al., 1965a, b).

Appropriately-timed corrective surgery is ideal if the defect can be closed with a low operative mortality and no late sequelae. Our studies indicate that nearly all our patients have done well after operation, but they were carefully selected, i.e. operation was restricted to patients with a left-toright shunt of more than 40 per cent, the optimal age for operation was 5 years, and it was undertaken at a younger age only if severe symptoms or recurrent respiratory infections were present. Earlier operation and the more frequent use of banding in Type 3A infants who have severe symptoms before their first birthday should prevent severe intimal fibrosis.

Pulmonary artery banding is indicated in infants who suffer from repeated respiratory infections, severe cardiac failure, or gross physical underdevelopment, and who do not respond to medical management; and in infants in whom there is evidence of increasing pulmonary vascular resistance (Muller and Dammann, 1952; Grainger et al., 1967). There is evidence that banding of the pulmonary artery improves the pulmonary vascular disease and the clinical status (Dammann et al., 1961). Young infants having corrective operations often die, particularly under the age of 6 months (Cartmill et al., 1966; Hallman, Cooley, and Bloodwell, 1966); but this is improving, and one group has reported a low mortality (Sigmann, Stern, and Sloan, 1967).

Children and infants with a small left-to-right shunt should be treated conservatively: if they have a high pulmonary vascular resistance, then an operation will confer a limited benefit and the time for operation has passed; if they have a low pressure then the prognosis is good and spontaneous closure is probable.

\section{SUMMARY}

Cardiac catheterization was undertaken one year after closure of an isolated ventricular septal defect in 34 patients. The patients were divided into different pre-operative groups according to their pulmonary arterial pressure. Thus patients with Type 1, 2, and 3 defects had mild, moderate, or severe pulmonary arterial hypertension, with a systolic pressure of $0-40,40-80$, and more than 80 per cent of the systolic pressure in a systemic artery. The patients were then subdivided according to the pulmonary blood flow. Thus Type 1A had a minute left-to-right shunt (less than 10\%), Type 1B a moderate shunt (10-40\%), and Type 1C a large shunt (greater than $40 \%$ ). Similarly, 
Type 3 was subdivided into patients with a large left-to-right shunt (greater than $40 \%$ ) and Type 3B where the left-to-right shunt was less than 40 per cent of bidirectional. Of the 34 patients, 2 had Type 1B, 5 had Type 1C, 9 had Type 2, 11 had Type 3A, and another 7 had significant obstruction to the outflow tract of the right ventricle, which needed correction (Type 1C with gradient). All the patients are now free of symptoms, they have varying degrees of incomplete right bundlebranch block, and the $x$-ray has shown reduction in heart size and pulmonary markings. Pulmonary arterial pressure fell in all the patients but there was little change in the ratio of pulmonary to systemic vascular resistance in patients with Type 1B, 1C, or 2 ventricular septal defect. A variable response was noticed in Type $3 \mathrm{~A}$ patients. There was a conspicuous increase in resistance in one, slight increase in 2, no change in 4 , and a decrease in 4 patients.

The reasons for these changes are discussed and suggestions are made about the correct timing for operations in these children.

We are grateful to Mr. R. P. Hewitson who performed some of the operations, to Mrs. C. M. Hall and Mrs. G. M. Ball for secretarial assistance, and to Dr. J. G. Burger, Medical Superintendent of Groote Schuur Hospital, for permission to publish. The South African Council for Scientific and Industrial Research and the City Council of Cape Town provided financial support for this study.

\section{REFERENCES}

Adams, P., Anderson, R. C., Meyne, N., and Lillehei, C. W. (1961). Physiological changes after closure of ventricular septal defects. $\mathcal{F}$-Lancet, 81, 497.

Anderson, R. A., Levy, A. M., Naeye, R. L., and Tabakin, B. S. (1967). Rapidly progressing pulmonary vascular obstructive disease. Association with ventricular septal defects during early childhood. Amer. F. Cardiol., 19, 854.

Arcilla, R. A., Agustsson, M. H., Bicoff, J. P., Lynfield, J., Weinberg, M., Fell, E. H., and Gasul, B. M. (1963). Further observations on the natural history of isolated ventricular septal defects in infancy and childhood. Serial cardiac catheterization studies in 75 patients. Circulation, 28, 560.

Auld, P. A. M., Gibbons, J. E., and McGregor, M. (1963). Vasomotor tone in the pulmonary vascular bed in patients with left-to-right shunts. Brit. Heart f., 25, 257.

Beck, W., Schrire, V., and Vogelpoel, L. (1964). The value of phonocardiography in the assessment of the surgical closure of ventricular septal defect. Amer. Heart $\mathcal{F}$., 67, 742 .

Bergofsky, E. H., Lehr, D. E., and Fishman, A. P. (1962). The effect of changes in hydrogen ion concentration on the pulmonary circulation. f. clin. Invest., 41, 1492.

Bloomfield, D. K. (1964). The natural history of ventricular septal defect in patients surviving infancy. Circulation, 29, 914.

Braunwald, N. S., Braunwald, E., and Morrow, A. G. (1962). The effects of surgical abolition of left-to-right shunts on the pulmonary vascular dynamics of patients with pulmonary hypertension. Circulation, 26, 1270.

Burton, A. C. (1951). On the physical equilibrium of small blood vessels. Amer. F. Physiol., 164, 319.

Cartmill, T. B., DuShane, J. W., McGoon, D. C., and Kirklin, J. W. (1966). Results of repair of ventricular septal defect. F. thorac. cardiovasc. Surg., 52, 486.

Dammann, J. F., Jr., and Ferencz, C. (1956). The significance of the pulmonary vascular bed in congenital heart disease. III. Defects between the ventricles or great vessels in which both increased pressure and blood flow may act upon the lungs and in which there is a common ejectile force. Amer. Heart f., 52, 210.

-, MacEachen, J. A., Thompson, W. M., Jr., Smith, R., and Muller, W. H. (1961). The regression of pulmonary vascular disease after the creation of pulmonary stenosis. F. thorac. cardiovasc. Surg., 42, 722.

Edwards, J. E. (1959). Discussion. In Pulmonary Circulation: An International Symposium, 1958, p. 242. Ed. by W. R. Adams and I. Veith. Grune and Stratton, New York.

- (1967). Ventricular septal defect. Unsolved problems. Amer. F. Cardiol., 19, 832.

Farrar, J. F., and Dunlop, I. C. (1965). The natural history of children suffering from ventricular septal defect and pulmonary hypertension. Aust. Ann. Med., 14, 130.

Fishman, A. P. (1961). Respiratory gases in the regulation of the pulmonary circulation. Physiol. Rev., 41, 214.

Gotsman, M. S. (1966). Increasing obstruction to the outflow tract in Fallot's tetralogy. Brit. Heart f., 28, 615.

Grainger, R. G., Nagle, R. E., Pawidapha, C., Robertson, D. S., Taylor, D. G., Thornton, J. A., Verel, D., and Zachary, R. B. (1967). Pulmonary artery banding for ventricular septal defect. Brit. Heart f., 29, 289.

Hallman, G. L., Cooley, D. A., and Bloodwell, R. D. (1966). Two-stage surgical treatment of ventricular septal. defect: Results of pulmonary artery banding in infants. and subsequent open-heart repair. $\mathcal{F}$. thorac. cardiovasc. Surg., 52, 476.

Harris, P., and Heath, D. (1962). The Human Pulmonary Circulation: its Form and Function in Health and Disease, p. 184. Livingstone, Edinburgh.

$\longrightarrow,-$ and Apostolopoulos, A. (1965). Extensibility of the pulmonary trunk in heart disease. Brit. Heart f., 27, 660 .

Heath, D., and Edwards, J. E. (1958). The pathology of hypertensive pulmonary vascular disease. A description of six grades of structural changes in the pulmonary arteries with special reference to congenital septal defects. Circulation, 18, 533.

-, Helmholz, H. F., Jr., Burchell, H. B., DuShane, J. W., and Edwards, J. E. (1958a). Graded pulmonary vascular changes and hemodynamic findings in cases of atrial and ventricular septal defect and patent ductus arteriosus. Circulation, 18, 1155.

$\longrightarrow, \frac{}{-}, \frac{1}{\longrightarrow}$, Kirklin, J. W., and Edwards, J. E. (1958b). Relation between structural changes in the small pulmonary arteries and the immediate reversibility of pulmonary hypertension following closure of ventricular and atrial septal defects. Circulation, 18, 1167.

Hoffman, J. I. E., and Rudolph, A. M. (1965). The natural history of ventricular septal defects in infancy. Amer. F. Cardiol., 16, 634.

Kidd, L., Rose, V., Collins, G., and Keith, J. (1965a). Ventricular septal defect in infancy: A hemodynamic study. Amer. Heart F., 69, 4.

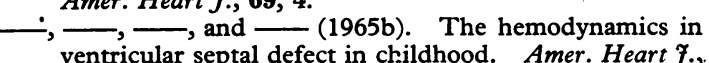
70, 732 . 
Kimball, K. G., and Mcllroy, M. B. (1966). Pulmonary hypertension in patients with congenital heart disease. Pre- and postoperative hemodynamics, pulmonary function, and criteria for surgical closure of defects. Amer. f. Med., 41, 883.

Lillehei, C. W., Levy, M. J., Adams, P., and Anderson, R. C. (1964). High-pressure ventricular septal defects. $\mathcal{F}$. Amer. med. Ass., 188, 949.

Lucas, R. V., Adams, P., Anderson, R. C., Meyne, N. G., Lillehei, C. W., and Varco, R. L. (1961). The natural history of ventricular septal defect. A serial physiologic study. Circulation, 24, 1372.

Muller, W. H., and Dammann, J. F., Jr. (1952). The treatment of certain congenital malformations of the heart by the creation of pulmonic stenosis to reduce pulmonary hypertension and excessive pulmonary blood flow. Surg. Gynec. Obstet., 95, 213.

Naeye, R. L. (1965). Children at high altitude: Pulmonary and renal abnormalities. Circulat. Res., 16, 33.

Rudolph, A. M., Mesel, E., and Levy, J. M. (1963). Epinephrine in the treatment of cardiac failure due to shunts. Circulation, 28, 3.

—, Scarpelli, E. M., Golinko, R. J., and Gootman, N. L. (1964). Hemodynamic basis for clinical manifestations of patent ductus arteriosus. Amer. Heart f., 68, 447.

Schrire, V., Vogelpoel, L., Beck, W., Nellen, M., and Swanepoel, A. (1965). Ventricular septal defect: the clinical spectrum. Brit. Heart f., 27, 813.

Sigmann, J. M., Stern, A. M., and Sloan, H. E. (1967). Early surgical correction of large ventricular septal defects. Pediatrics, 39, 4.

Stanton, R. E., and Fyler, D. C. (1961). The natural history of pulmonary hypertension in children with ventricular septal defects assessed by serial right-heart catheterization. Pediatrics, 27, 621.

Vogel, J. H. K., Grover, R. F., and Blount, S. G. (1967a). Pathophysiologic correlations in patients with ventricular septal defect and increased pulmonary vascular resistance (Abstract). Amer. F. Cardiol., 19, 154.

-, McNamara, D. G., and Blount, S. G. (1967b). Role of hypoxia in determining pulmonary vascular resistance in infants with ventricular septal defects. Amer. $\mathcal{F}$. Cardiol., 20, 346.

-, Pryor, R., and Blount, S. G. (1964). The cardiovascular system in children from high altitude. F. Pediat., $64,315$.

Vogelpoel, L., Schrire, V., Beck, W., Nellen, M., and Swanepoel, A. (1962). Variations in the response of the systolic murmur to vasoactive drugs in ventricular septal defect, with special reference to the paradoxical response in large defects with pulmonary hypertension. Amer. Heart F., 64, 169.

Wagenvoort, C. A. (1960). Vasoconstriction and medial hypertrophy in pulmonary hypertension. Circulation, 22, 535.

—, Nauta, J., van der Schaar, P. J., Weeda, H. W. H., and Wagenvoort, N. (1967). Effect of flow and pressure on pulmonary vessels: A semi-quantitative study based on lung biopsies. Circulation, 35, 1028.

—, Neufeld, H. N., DuShane, J. W., and Edwards, J. E. (1961). The pulmonary arterial tree in ventricular septal defect: A quantitative study of anatomic features in fetuses, infants, and children. Circulation, 23, 740.

Weidman, W. H., DuShane, J. W., and Kincaid, O. W. (1963). Observations concerning progressive pulmonary vascular obstruction in children with ventricular septal defects. Amer. Heart F., 65, 148.

West, J. B., and Dollery, C. T. (1960). Distribution of blood flow and ventilation-perfusion ratio in the lung, measured with radioactive $\mathrm{CO}_{2}$. F. appl. Physiol., 15, 405.

,-- , and Heard, B. E. (1964). Increased vascular resistance in the lower zone of the lung caused by perivascular oedema. Lancet, $2,181$.

Wood, P. (1958). Pulmonary hypertension with special reference to the vasoconstrictive factor. Brit. Heart $\mathcal{F}$., $20,557$.

- (1959). The vasoconstrictive factor in pulmonary hypertension. In Pulmonary Circulation, p. 294. Ed. by W. R. Adams and I. Veith. Grune and Stratton, New York.

—, Magidson, O., and Wilson, P. A. O. (1954). Ventricular septal defect, with a note on acyanotic Fallot's tetralogy. Brit. Heart f., 16, 387. 